\title{
S5ynthesis
}

International Scientific Conference of IT and Business-Related Research

\section{ANALIZA KVALITETA RAZLIČITIH FORMATA DIGITALNE SLIKE}

\author{
ANALYSIS OF THE QUALITY OF DIFFERENT DIGITAL IMAGE FORMATS
}

\author{
Ratko Ivković1, Ivana Milosević2, Tatjana Petrović ${ }^{3}$, Smiljana Bijelović ${ }^{4}$, Nebojša Ivković ${ }^{5}$ \\ ${ }^{1}$ Departman za Elektrotehničko i Računarsko inženjerstvo, Fakultet Tehničkih Nauka, Univerzitet u Prištini, Kosovska Mitrovica, Srbija \\ ${ }^{2}$ SP Audio i video tehnologije, Visoka škola elektrotehnike i računarstva, Beograd, Srbija \\ ${ }^{3}$ Kriminalističko-policijska akademija, Beograd, Srbija \\ ${ }^{4}$ Evropski univerzitet, Brcko Distrikt, Bosna i Hercegovina \\ ${ }^{5}$ Visoka poslovno - tehnička škola, Užice, Srbija
}

\begin{abstract}
Apstrakt:
Ovaj rad pruža analizu kvaliteta novih i za sada nedovoljno korišćenih formata digitalne slike. Pored brojnih idejnih rešenja načina zapisa digitalne slike, danas je u upotrebi veoma mali broj formata zapisa. Analiza je sprovedena uz pomoć matematičkih alata CVIPtools i Matlab softverskog paketa. Slike koje su obuhvaćene istraživanjem predstavljaju slike standardnih karakteristika za oblast digitalne obrade slike, pa su stoga i dobijeni rezultati merljivi i daju validne rezultate za poređenje sa ostalim radovima iz ove oblasti.
\end{abstract}

\section{Ključne reči:}

BPG, Super PNG, Tiny PNG, Tiny JPEG, formati digitalne slike.

\section{Abstract:}

This paper provides the quality analysis of new and insufficiently explored digital image formats. Besides numerous ideal solutions of recording digital images, there is still a very small number of file formats being used. The analysis was carried out by means of mathematical tools CVIPtools and Matlab software. Images used in the research are are those with standard features in the filed of digital image processing, which makes the results obtained measurable and provides valid results for comparison with other related works in the field.

\section{Key words:}

BPG Super PNG, PNG Tiny, Tiny JPEG, digital image formats.

\section{Zahvalnica:}

Ovaj rad je podržan od strane Ministarstva prosvete i nauke Republike Srbije (projekat III44006).

\section{UVOD}

Pozicioniranje nekog formata digitalne slike na tržištu prvobitno zavisi od jednostavnosti algoritma, prustupačnosti formata za različite uređaje, a zatim od kvaliteta reprodukovane slike. Primer za ovo se može naći kroz GIF format slike koji je početkom 1990-tih definisao skoro sve pod jednim formatom (Jackson \& Hannah, 1993). Transparentna pozadina, animacija i jednostavnost reprodukcije su bili razlozi da uprkos tome što se plaćala licenca za njegovo korišćenje, bude primarni format digitalne slike (Amer et al., 1999). Ova situacija se održala sve dok JPEG format nije preuzeo primat na Internetu kao vodeći format slike (Harris \& Wright, 1991; Lan et al., 1999), firma Macromedia na polju animacija (Scott, 2000; Wei, 2009), a PNG format sa besplatnom licencom u oblasti transparentnih segmenata digitalne slike (ISO, 2004). Adobe kupuje kompaniju Macromedia 2005. godine, pa dolazi do promene u oblasti fleša, dodavanjem skripti u programiranju (action script) (Adobe, 2005). Na ovaj način, nakon 25 godina vladavine, GIF format je pomeren sa trona (Gelbmann, 2013). Danas se 65\% slikovnih sadržaja u digitalnoj formi nalazi u JPEG formatu slike (Pessina, 2010). Sve do pojave eksperimentalne verzije BPG formata JPEG je bio neprikosnoven u odnosu kvalitet/kompresija (Marcellin et al, 2010; Maini \& Mehra, 2010).

\section{TEORIJSKI OKVIR}

BPG

BPG (Better Portable Graphics) predstavlja novi format zapisa digitalne slike. Cilj uvođenja ovog formata je da se zameni JPEG format u situacijama kada kvalitet predstavlja problem. Veoma visok stepen Lossless kompresije je ono po čemu se ovaj format razlikuje od drugih, što proističe iz činjenice da ima podršku za HEVC video kompresiju (Bross, 2012). Iako figurira visok stepen kompresije, BPG pruža mogućnost od 8 do 14 bita po kanalu, sto praktično znači da poseduje zapis bitske dubine 42 bita za dinamički opseg. Kada je u pitanju način zapisa, BPG se ugleda na JPEG format slike, pa je zastupljen zapis u YCbCr 4:2:0, 4:2:2, 4:4:4, a što se tiče kolor prostora tu figuriše YCgCo i CMYK (Mostafa et al, 2011; Rodriguez, 1995). Takođe, veoma je bitno napomenuti da BPG podržava suplementarne fajlove kao što su EXIF, ICC i XMP (TSR, 2015). Podrška Alfa kanala i podrška za animaciju su jako bitne, jer je pored visokog stepena kompresije, te tri osobine razlikuju BPG od JPEG formata digitalne slike. Samim tim može se reći da BPG ima osobine PNG formata kada je u pitanju transparentnosti, GIF formata po pitanju animacije, bolje osobine kompresije od JPEG formata, dok se upravo razvija podrška za veb pretraživače, pa se sa razlogom 
očekuje da ovaj format od naredne godine bude standardizovan i da zameni JPEG format.

\section{SUPER PNG}

Ovaj format digitalne slike se zasniva na izmenjenom PNG algoritmu sa losslessly kompresijom. Tako da konverzija u ovaj format se zasniva na što manjim gubicima. Odnosno kada se uzme u obzir da prilikom zapisa dolazi do konverzije sa 24 bitskog na 32 bitsku dubinu zapisa, greška koja nastaje kompresijom se može potpuno zanemariti (Compress PNG, 2015). Koraci u algoritmu su prikazani na Slici 1 respektivno.

a)

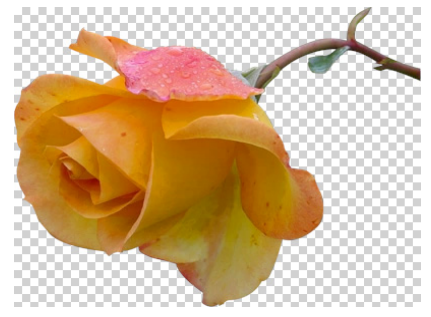

b)

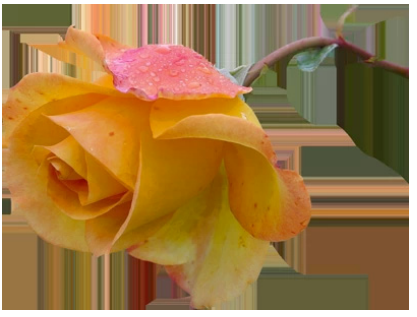

c)

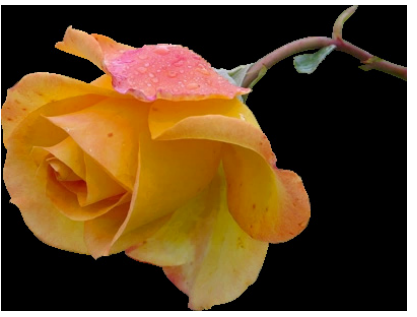

Slika 1. Postupak "čišćenja" slike od neželjenih piksela

a) učitana originalna slika, b) definisanje transparentne oblasti, c) konverzija transparentne oblasti

U prvom koraku nakon učitavanja PNG slike sa transparentnom površinom, dolazi do njene konverzije u sliku sa tridesetdvobitnom dubinom zapisa. Nakon toga algoritam detektuje transparentu oblast, i konvertuje je u oblast sa vrednošću $0 \mathrm{u}$ RGBA modu zapisa. Što znači da će u ovom koraku kompletna trasparentna oblast imati osobinu crne boje. Ovo se radi iz razloga greške transparentne oblasti, jer se u velikom broju slučajeva „neželjeni“ pikseli upravo nalaze i u transparentnoj oblasti (šum, greška u definisanju oblasti, greška kompresije, itd.). Nakon opisanih postupaka slika se može zapisati u jednom od 11 kvantizacionih nivoa kompresije u spng formatu.

\section{TINY PNG}

Nasuprot Super PNG formata slike, Tiny PNG koristi RGB mod zapisa slike sa predikcijom Alfa kanala. Za razliku od prethodnog zapisa ovde Alfa kanal se koristi kao osnova za množe- nje RGB zapisa (Tiny PNG, 2015). Tako npr. vrednost 0.5(0.0, $1.0,0.0)$ predstavlja vrednost crvene $0 \%$, zelene $100 \%$ i plave od $0 \%$ sa $50 \%$ transparentnosti. Ovakav način zapisivanja ima prednost u količini memorije za razliku od punog zapisa, mada dolazi do gubitka kvaliteta u pojedinim slučajevima.

\section{TINY JPEG}

Svoj rad bazira na JPEG osnovnom algoritmu pri čemu se vrši analiza slike kroz teksture i boje (Tiny JPEG, 2015; Brodatz, 1966). Nakon toga pribegava kompresiji date slike na osnovu tih podataka. Sledeći korak ima za cilj ispravljanje grubih prelaza na slici, tako da izlazna slika ne poseduje drastične razlike u vrednosti susednih piksela.

\section{HDF (HIERARCHICAL DATA FORMAT)}

Glavna odlika HDF načina zapisa slike je da se bazira na hijerarhijskom rasporedu zapisa "slojeva“ u digitalnoj slici. U toj hijerarhijskom zapisu najveći primat imaju simboli, zatim numerički objekti pa grafičke strukture (Lee \& Spence, 2002). Pa u situacijama kada je potrebna strukturalna raspodela objekata u digitalnoj slici, najpoželjnije je koristiti ovaj vid zapisa. HDF je naročito popularan u pojedinim naučnim krugovima pri zapisu slojevitih elemenata slike (HDF Group, 2015). Na primer, pri snimanju u spektroskopiji kada svaki sloj ovako struktuirane slike označava tačno definisani opseg talasnih dužina.

\section{IFF (INTERCHANGE FILE FORMAT)}

Jedan od formata digitalne slike koji se najduže zadržao na tržištu, datira iz 1985. godine kao format digitalne slike predodređen za Amiga kompjutere. Danas, u izmenjenom obliku ima podršku kompresije sa malo gubitaka i InterLeaved bitskom mapom, sa tridesetdvobitnom dubinom zapisa (Amiga, 2010). Iz IFF formata digitalne slike nastao je TIFF format (nakon što je 1991. godine Microsoft kupio licencu), koji se danas koristi kao jedan od referentnih formata u analizi digitalne obrade slike.

\section{PBM (PORTABLE BIT MAP)}

Format slike koji se zasniva na bitskoj mapi kao svojoj osnovi. Visina i širina slike se može podešavati na osnovu decimalnog zapisa prema ASCII kodu. Zapis se vrši u monohromatskim slikama sa tri odvojena kanala, koji se predstavljaju kao jedan RGB signal. Svaki bit predstavlja piksel, pri čemu u ovom slučaju 1 predstavlja crnu boju, a 0 belu. Redosled piksela se zapisuje sa leva na desno, dok je redosled njihovog skladištenja u okviru datoteke prema njihovoj težini. Na kraju dekoder čita redom piksele i sortira ih na bitskoj mapi (PBM, 2013). Ovaj format slike je napravljen kao alternativa BMP formatu slike.

\section{METODOLOGIJA}

Rad se bazira na standardima koji se koriste u teorijskom razmatranju oblasti digitalne obrade slike. Kvadratne rezolucije $512 \times 512$, sa 96 tačaka po inču za horizontalnu i vertikalnu rezoluciju, 24 bitska dubina zapisa ( 8 bita po RGB kanalu), u TIFF formatu. Ovaj format je izabran iz razloga što se ne bazira na kompresiji, pa su rezultati dobijeni analizom verodostojni, i merljivi sa ostalim radovima iz ove oblasti (Ivković et al., 2015). 


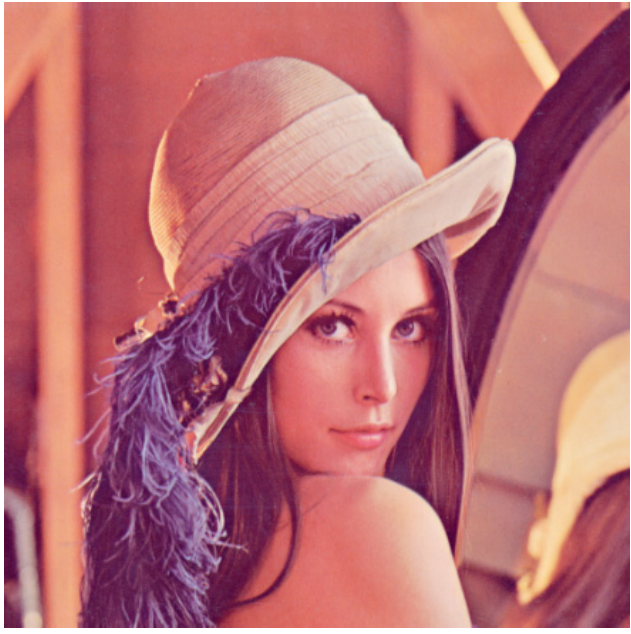

Slika 2. Originalna slika bez transparentnih segmenata $(768 \mathrm{~kb})$

Analiziran je kvalitet različitih formata sa slikom bez transparentnih segmenata, pa se tada utvrđuje kvalitet punog zapisa bez postojanja Alfa kanala, pri istim stepenima kompresije pa se zbog toga greška kompresije zanemaruje.

Treba napomenuti, da za sada ne postoji konačna verzija BPG formata slike, već da je za sada u obliku koda otvorene licence u C++ programskom jeziku, i da je za potrebe ovog rada izvršeno prilagođenje za potrebe rada u Matlabu da bi se ovaj format mogao posmatrati kao digitalni signal i meriti njegove karakteristike.

\section{REZULTATI}

Dobijeni rezultati koji su prikazani na graf. 1, daju uvid u entropiju digitalne slike, ili potencijal. Pošto je maksimalna vrednost entropije za dvadesetčetvorobitnu dubinu zapisa 8 bita, a vrednost originalne slike 7.7502 bita, lako se može utvrditi koliko se gubi ili dobija nakon konvertovanja u odnosu na originalnu sliku. Dobru informaciju predstavlja to što skoro svi formati zadržavaju gotovo identičnu vrednost potencijala slike, pri čemu je to odstupanje manje od $\pm 1.5 \%$.

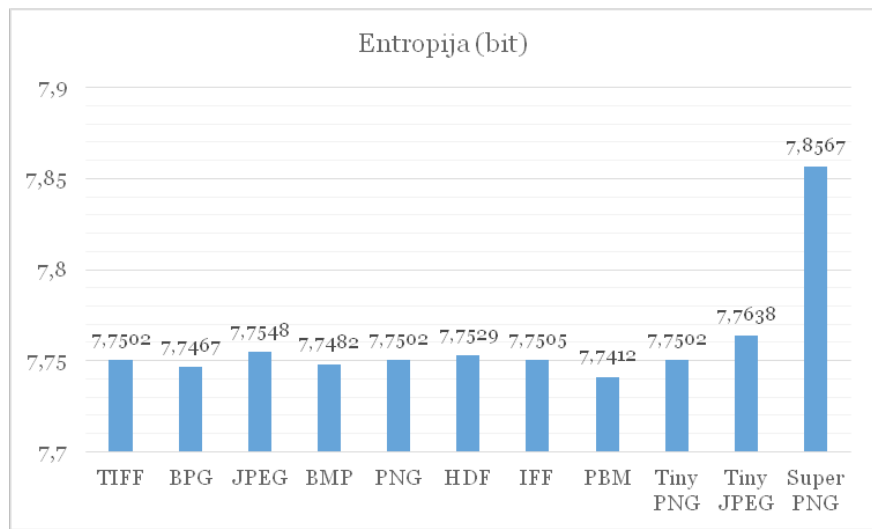

Grafikon 1. Vrednosti entropije za posmatrane slike

Metod strukturalne sličnosti je možda jedan od najverodostojnih pokazatelja sličnosti originalne slike sa rekonstruisanom. Pri čemu poredi osvetljenje u slici, strukturu slike i kontrast slike. Pošto tokom analize dobijene slike nisu podvrgnute promeni rezolucije, metod strukturalne sličnosti će dati poređenje osvetljenja i kontrasta originala sa dobijenim slikama. Graf. 2. pokazuje vrednosti strukturalne sličnosti rekonstruisanih slika u odnosu na original za slučaj slika bez transparentnih segmenata. Maksimalno odstupanje se može primetiti kod BPG formata slike i iznosi 5.13\%, mada uzevši u obzir da se primenjuje visok stepen kompresije kao kod HEVC kodeka, ova greška u osvetljenju i kontrastu je sasvim prihvatljiva. Formati JPEG, Tiny PNG, Tiny JPEG i Super PNG daju odstupanje od 1.6-3.6\%, dok ostali formati daju gotovo identičnu sličnost sa originalnom slikom.

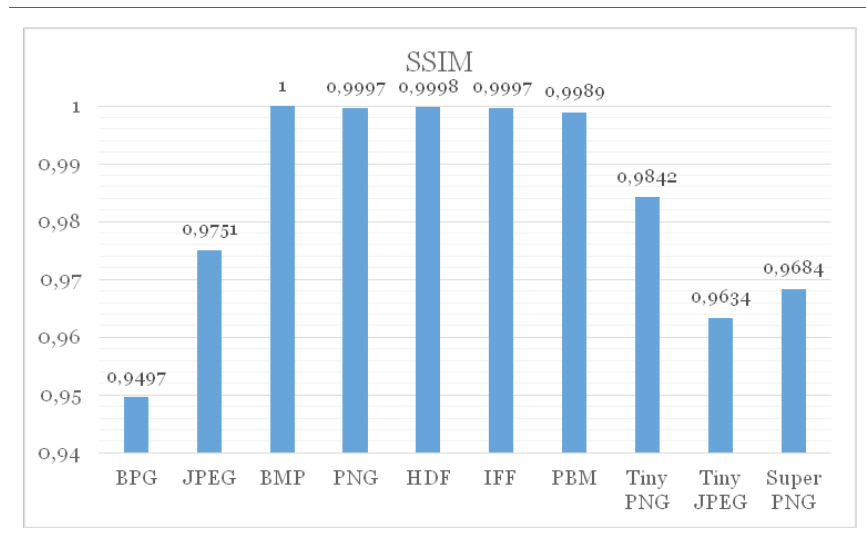

Grafikon 2. Vrednosti SSIM za posmatrane slike

Memorija rekonstruisanih slika je prikazana na grafikonu 3. Kao što se može primetiti iz grafikona format HDF zauzima najviše memorije prilikom zapisa, upravo zbog činjenice da hijerarhijski zapisuje sliku, pa je memorija duplo veća za razliku od izvornog fajla, dok sa druge strane najveća ušteda u memoriji se može uočiti kod novog formata slike BPG. Ta ušteda je 42.9 puta veća što predstavlja značajnu informaciju, i govori da će u bliskoj budućnosti ovaj format igrati značajnu ulogu na polju digitalne obrade slike. Nakon toga slede formati JPEG, Tiny JPEG, Super PNG i Tiny PNG, dok ostali formati zadržavaju približno istu količinu memorije i nakon kompresije.

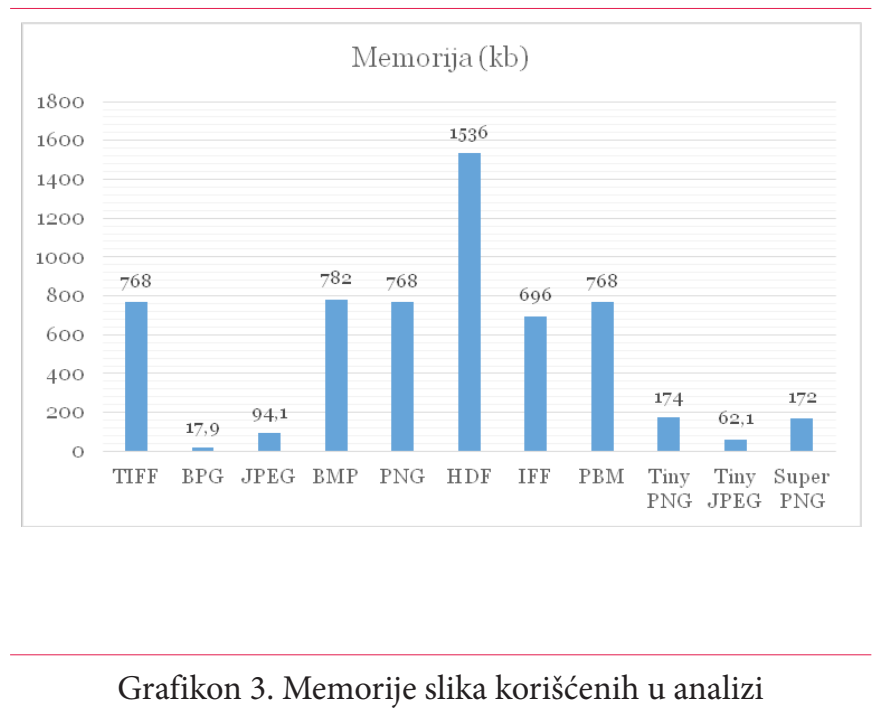

Mera promene vrednosti piksela na određenom segmentu slike, ili mera nivoa detalja pokazuje učestalost promene vrednosti piksela. Što je ta promena veća nivo detalja je veći i obrnuto. Kao što se može uočiti sa grafikona 4 . jedino formati BPG i Tiny JPEG daju nižu vrednost nivoa detalja za posmatrane Slika 3. 


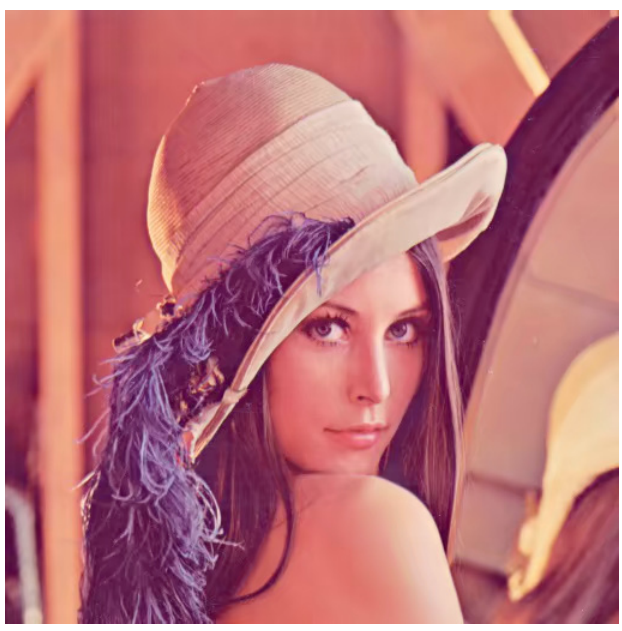

Slika 3. BPG format $(17.9 \mathrm{~kb})$

Ovo se pravda velikim nivoom kompresije koja je primenjena u ovim formatima. Dok sa druge strane formati Tiny PNG i Super PNG daju veći nivo detalja od originalne slike. Ovako nešto se može objasniti postupcima koji se primenjuju u nastajanju formata. Tiny PNG koristi predikciju (multiplekser), koji menja ulogu Alfa kanala, usled čega dolazi do greške, jer ne važi identičan koeficijent množenja za sva tri kanala po svakom pikselu, već se on približno računa na osnovu posebnog algoritma. Super PNG kao i prethodni format ima izvesnu grešku u samom algoritmu, jer određene oblasti sam algoritam predstavlja kao transparentne i menja sa crnom bojom, i usled toga nastaje mala greška. U prethodna dva slučaja, greške kompresije možemo predstaviti kao šum koji se javlja u slici, pa je zato bilo neophodno izvršiti analizu direktnog odnosa signal/šum (SNR). Upravo to pokazuje grafikon 5 gde se može uočiti koji algoritam daje najveći šum nakon kompresije. Upravo iz objašnjenih razloga formati Tiny PNG i Super PNG imaju najveći stepen šuma nakon kompresije, dok sa druge strane iako je BPG podvrgnut visokom stepenu kompresije nivo šuma u slici se meri promilima. Ostali formati prikazuju zanemarljivu promenu nivoa detalja nakon kompresije, pa sa tim i zanemarljiv nivo šuma.

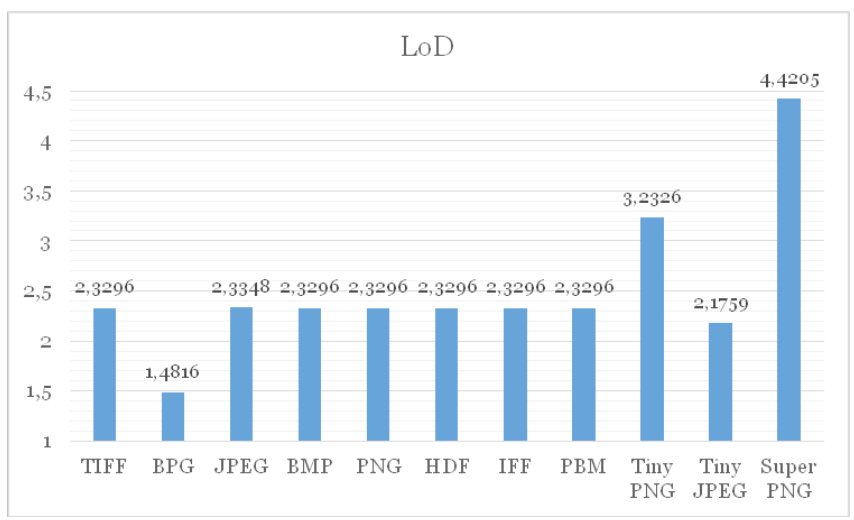

Grafikon 4. Vrednosti LoD za posmatrane slike

Upravo iz razloga koji su definisani grafikonima 4 i 5 vrednost vršnog odnosa signal/šum se može posmatrati samo za formate slika u kojima se pojavljuje određena količina šuma. Uzevši u obzir da se u digitalnoj obradi slike kvalitetan prenos tretira iznad $35 \mathrm{~kb}$. Na osnovu grafikona 6. se može konstatovati da svi formati u ovom slučaju su na granici kvalitetnog prenosa.

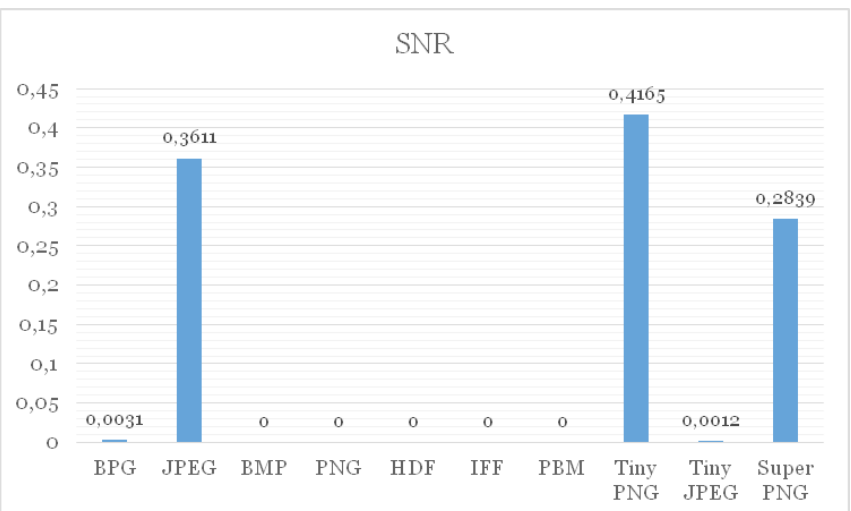

Grafikon 5. Vrednosti SNR za posmatrane slike

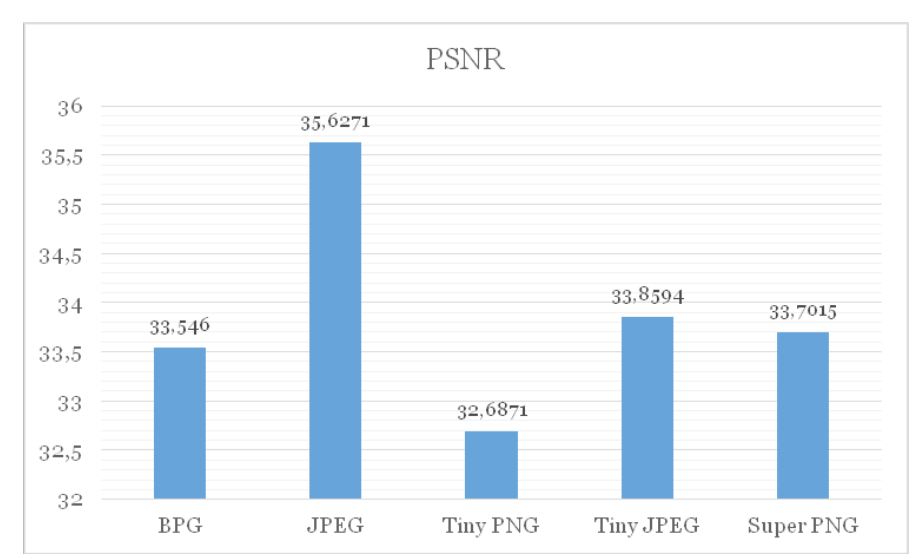

Grafikon 6. Vrednosti PSNR za posmatrane slike

\section{ZAKLJUČAK}

Ovaj rad daje komparativnu analizu između formata slike koji imaju najširu primenu na tržištu, i formata koji pokrivaju veoma mali deo tržišta. Uzevši u obzir celokupno istraživanje, može se zaključiti da za sada eksperimentalni formati BPG i Super PNG pri svim testovima daju najbolje rezultate. Super PNG iz razloga smanjenja memorije od 4.4 puta, povećanja potencijala slike, kao i nivoa detalja, uz mali procenat pojavljivanja šuma u slici. BPG daje ogromnu uštedu u memoriji, dok praktično skoro zadržava sve ostale parametre u sličnim granicama kao i ostali formati, uz jedinu manu, a to je trajanje procesa konverzije, koje je 7.6 puta duže u proseku za razliku od ostalih formata. Na redukciji vremena kompresije će se sigurno raditi u narednom periodu, pa će BPG format moći u pravoj meri da zameni JPEG.

\section{LITERATURA}

Adobe. (2005). Adobe to acquire Macromedia. Preuzeto 04.12.2014. sa https://www.adobe.com/aboutadobe/invrelations/adobeandmacromedia.html 
Amer, P.D., Iren, S., Sezen, G.E., Conrad, P.T., Taube, M., \& Caro, A. (1999). Network-Conscious GIF Image Transmission Over the Internet. Computer and Information Sciences Department. DE 19716 USA. Newark:University of Delaware.

Amiga. (2010). Amiga file format. Preuzeto 19.12.2014. sa http:// lclevy.free.fr/amiga/formats.html

Brodatz, P. (1966). Textures: A Photographic Album for Artists and Designers. Toronto: Dover Publ.

Bross, B., Han, W.-J., Sullivan, G. J., Ohm, J.-R., \& Wiegand, T. (2012). High Efficiency Video Coding (HEVC) Text Specification Draft 9. Document JCTVC-K1003. ITU-T/ISO/ IEC Joint Collaborative Team on Video Coding (JCT-VC).

Compress PNG. (2015). Super PNG image support documentation. Preuzeto 26.12.2014. sa http://compresspng.com/

Gelbmann, M. (2013). The PNG image file format is now more popular than GIF Preuzeto 04.12.2014. sa http://w3techs. com/blog/entry/the_png_image_file_format_is_now_ more_popular_than_gif.

Harris, F., \& Wright, D. (1991). The JPEG Algorithm for Image Compression: A Software Implementation and some Test Results. Conference Record Twenty-Fourth Asilomar Conference on Signals, Systems and Computers. DOI: 10.1109/ ACSSC.1990.523462.

HDF Group. (2015). Preuzeto 26.12.2014. sa http://www.hdfgroup.org/

ISO (2004). Information technology -- Computer graphics and image processing -- Portable Network Graphics (PNG): Functional specification. ISO/IEC 15948:2004. TC/SC: ISO/ IEC JTC 1/SC 24. ICS: 35.140.

Ivković, R., Milošević, I., Gara, B., Pavlović, M., \& Miljković, D. (2015). Analysis of Digital Image Segments Through the Standard Deviation and Level of Detail. Međunarodni naučno-stručni Simpozijum. INFOTEH-JAHORINA 2015.

Jackson, D.J., \& Hannah, S.J. (1993). Comparative analysis of image compression techniques. Twenty-Fifth Southeastern Symposium on System Theory, 1993. Proceedings SSST ' 93 , pp. 513-517. DOI: 10.1109/SSST.1993.522833.

Lan, T.-H., Tewflk, A.H., Hu, P.-C. (1999). JPEG transcompressor and Internet applications. IEEE Workshop on Signal Processing Systems, pp. 400-409. DOI: 10.1109/ SIPS.1999.822345.
Lee, K.-P., \& Spence, P.L. (2002). view_HDF: visualization and analysis tool for hierarchical data format files. OCEANS '02 MTS/IEEE, pp. 744-750. DOI: 10.1109/ OCEANS.2002.1192063.

Maini, R., \& Mehra, S. (2010). A Review on JPEG2000 Image Compression. International Journal of Computer Applications, 11(9), 43-47.

Marcellin, M. W., Gormish, M. J., \& Bilgin, A. (2000). An overview of JPEG-2000. Data Compression Conference:Proceedings, pp. 523-541. DOI: 10.1109/DCC.2000.838192.

Mostafa, A., Wahid, K., \& Ko, S-B. (2011). An efficient YCgCobased image compression algorithm for capsule endoscopy. 14th International Conference on Computer and Information Technology (ICCIT), pp. 219-222. DOI: 10.1109/ICCITechn.2011.6164787.

PBM. (2013). Preuzeto 19.12.2014. sa http://netpbm.sourceforge. net/doc/pbm.html

Pessina, L.A. (2010). JPEG changed our world. Preuzeto 04.12.2014. sa http://actu.epfl.ch/news/jpeg-changed-ourworld/

Rodriguez, M. (1995). A graphic arts perspective on RGB-toCMYK conversion. International Conference on Image Processing, pp. 319-322. DOI: 10.1109/ICIP.1995.537479.

Scott, C.J. (2000). Vector animation: Web-based software training on demand. IEEE Aerospace Conference Proceedings, pp. 473-479. DOI: 10.1109/AERO.2000.878256.

Tiny JPEG image support documentation. Preuzeto 24. 12. 2014. sa https://tinyjpg.com/

Tiny PNG. (2015). Image support documentation. Preuzeto 24. 12. 2014. sa https://tinypng.com/

TSR. (2015). Watermark Image Software image metadata support documentation. Preuzeto 26. 12. 2014. sa https://www. watermark-image.com/metadata.aspx

Wei, W. (2009). Flash Media Server and Its Application in the Simulator of VHF Marine Radio Station. International Conference on Information Engineering and Computer Science, pp. 1-4. DOI: 10.1109/ICIECS.2009.5363153. 